\title{
A MORTE DE IVAN ILITCH E AS DIRETIVAS ANTECIPADAS DA VONTADE: DIREITO E LITERATURA NUMA REFLEXÃO SOBRE MORTE DIGNA
}

\author{
Fernanda Leontsinis Carvalho Branco ${ }^{1 *}$
}

\section{RESUMO}

A obra clássica literária do poeta russo Lev Tolstói propõe uma reflexão sobre a morte e, consequentemente, sobre a vida, ao retratar os momentos finais de Ivan Ilitch, um juiz de instrução na Rússia Czarista. A novela pode ser relacionada com o tema jurídico das Diretivas Antecipadas da Vontade que permitem uma maior autonomia do paciente no processo de morrer. O presente ensaio busca, então, em uma relação entre Direito e Literatura, pensar a morte com dignidade.

Palavras-chave: A morte de Ivan Ilicht; Direito e Literatura; Diretiva Antecipada da Vontade; Lev Tólstoi; Cuidados Paliativos.

\section{THE DEATH OF IVAN ILYICH AND LIVING WILL: LAW AND LITERATURE IN A REFLECTION ON DIGNA DEATH}

\begin{abstract}
The classic literary work of the Russian poet Lev Tolstoy proposes a reflection on death and, consequently, on life, by portraying the final moments of Ivan Ilitch, an investigating judge in Tsarist Russia. The novel can be related to the legal theme of the Living Will that allow a greater autonomy of the patient in the process of dying. The present essay seeks, then, in a relationship between Law and Literature, to the understanding of death with dignity.
\end{abstract}

Key-words: The Death of Ivan Ilyich; Law and literature; Living Will; Leo Tolstoy; Palliative Care.

\section{INTRODUÇÃO}

A morte de Ivan Ilitch, obra literária publicada em 1886, retrata a vida e os momentos finais de um magistrado na Rússia pré-revolução bolchevique. Segundo a narrativa, Ivan Ilitch Golovin morreu aos quarenta e cinco anos de idade, no dia 04 de fevereiro de 1882 , acometido por uma enfermidade grave, não diagnosticada.

Em pouco menos de oitenta páginas, Tolstói reconstrói a vida de Ilitch que, segundo o narrador, "foi das mais simples e comuns e, ao mesmo tempo, das mais terríveis"

\footnotetext{
* Mestranda em Direito Constitucional pela UFC, na condição de bolsista Capes; endereço eletrônico: feleontsinis@gmail.com
}

Rev. de Direito, Arte e Literatura | e-ISSN: 2525-9911 | Evento Virtual | v. 6 | n. 1 | p. 21-38 | 
(TOLSTÓI, 2009, p. 17). No trabalho, o protagonista vivia imerso no mundo jurídico na certeza da neutralidade do método e no distanciamento das partes para a resolução do conflito, marcas da cultura legal da época em que o papel do juiz era limitado a aplicar mecanicamente o Direito.

Em casa, o casamento por conveniência que, no início, lhe reforçava o "caráter de vida leve, agradável, alegre e sempre decente" (TOLSTÓI, 2009, p. 23) que buscara ao longo de sua trajetória para aprovação pela sociedade tornou-se algo penoso e desagradável, fazendo-o imergir ainda mais nos ofícios que lhe eram impostos pela função pública.

Certo dia, Ivan Ilitch conseguiu uma promoção para o Ministério da Justiça. A esposa ficara feliz com a promoção e ambos reuniam-se fazendo planos para a nova vida que levariam com avanço na posição social. E a vida do protagonista que passara por um período turbulento de incertezas e questionamentos, ganhava, novamente, a alegria e a decência que lhe eram familiar.

No entanto, em meio à mudança e à reforma de sua nova casa, Ilitch sofreu uma queda que, de imediato, não lhe trouxe sofrimento, mas, passado um tempo, indica uma doença grave que lhe faz enfrentar a dor e angústia da certeza da morte.

Em Law and Literature, ao discorrer sobre o Direito na Literatura, Posner destaca que uma característica que faz com que grandes obras literárias perdurem no tempo, atravessando gerações e se tornem clássicos de leitura, é a universalidade: "os escritores conseguem dramatizar de maneira particularmente impressionante algum aspecto universal da condição humana que a ciência ainda não foi capaz de submeter sob seu domínio, como amor, medo ou morte" (POSNER, 2009, p. 28-29).

Indiscutivelmente, a novela russa se insere nessa concepção ao retratar majestosamente toda a dor física e emocional de deparar a morte, seja como o moribundo, seja como um familiar ou amigo. Para além da morte, Tolstói conduz a uma reflexão sobre a vida, sobre viver pela aprovação da sociedade, de uma forma alegre e decente como fez o seu protagonista ou viver de forma inocente e verdadeira, como a memória de Ilitch retoma a fase infanto-juvenil feliz de sua trajetória longe das veleidades e da hipocrisia da aristocracia russa.

A obra já foi objeto de análise sob diferentes perspectivas. Trindad e Rosenfield (2015), por exemplo, propuseram uma reflexão sobre a interpretação do Direito e o papel do juiz a partir da descrição de Ilitch como magistrado. Cecilio (2008) abordou a obra de Tolstói 
para tratar as múltiplas dimensões da gestão do cuidado, questionando estratégias gerenciais utilizadas atualmente nos sistemas público e particulares de saúde. A proposta deste artigo é abordar o tema central da obra literária: a morte, a partir de uma perspectiva jurídica das Diretivas Antecipadas da Vontade.

As diretivas são um documento unilateral feito pelo paciente que manifesta previamente a sua vontade sobre os cuidados médicos que deseja ou não receber em caso de possível incapacidade de relatar sua vontade. A regulamentação do instituto dá-se por uma Resolução do Conselho Federal de Medicina de 2009 (CFM, 2009) que também permite ao paciente determinar, previamente, um procurador de saúde: alguém de sua confiança para substituir-lhe a vontade em caso de incapacidade. O tema relaciona-se ao direito à morte com dignidade, reflexão que norteia A morte de Ivan Ilicth.

Ao longo da narrativa, o poeta russo aborda os processos de enfrentamento da terminalidade vividos pelo protagonista. Conforme (KÜBLER-ROSS, 2017), uma das precursoras na pesquisa sobre a morte e o processo de morrer, são cinco fases por que passam os pacientes: negação, quando o paciente recebe o diagnóstico da doença e custa a aceitá-lo; raiva, ao sentir como uma injustiça ter a vida interrompida abruptamente; barganha, quando se tenta algum tipo de acordo para evitar ou adiar o fim temido; depressão, com a progressão da doença, a negação e a raiva cedem lugar à tristeza e, por fim, aceitação, quando o indivíduo resigna-se com a terminalidade da vida.

Conquanto indiscutível a mortalidade, falar sobre ela ainda é motivo de estranhamento. Em um processo de higienização e distanciamento da morte ${ }^{2}$ e do luto porque passa a sociedade ocidental, discutir o fim da vida pode ser visto como algo melancólico, triste.

Contudo, necessário questionar e analisar a forma do morrer para garantir a dignidade nesse momento final da trajetória da vida.

\section{DIRETIVA ANTECIPADA DA VONTADE}

2 Sobre o tema morte, houve a realização de um programa de televisão, Direito \& Literatura, exibido pela TV Justiça, em 2018, com apresentação de Lênio Streck e com a participação de Mário Fleig, filósofo e psicanalista; Draiton Gonzaga de Souza, professor de Filosofia da PUCRS e Kathrin Rosenfield, professora de Filosofia e de Literatura da UFRGS como convidados. O vídeo encontra-se disponível em: <https://www.youtube.com/watch?v=G6SvjK25Siw>. Acesso em: 10 de abril de 2020. 
O envelhecimento da população é um fato incontestável que, se de um lado representa o triunfo da longevidade da vida, de outro, impõe novos desafios e políticas públicas para lidar com esse cenário. Segundo a Organização Mundial da Saúde, entre 2015 e 2050, a proporção da população mundial com mais de 60 anos quase dobrará de $12 \%$ para $22 \%$ e em $2050,80 \%$ das pessoas idosas viverão em países de baixa e média renda (OMS, 2002).

Com o aumento da expectativa de vida, há também o crescimento de doenças crônico-degenerativas. A pessoa idosa é acometida de estados de saúde complexos que diminuem sua autonomia. O que significa que profissionais de saúde devem adequar-se a esta nova realidade para continuar a cuidar dos enfermos de maneira humanizada. Essa preocupação com o envelhecimento da população e o tratamento médico destinado aos doentes fez crescer o estudo e a prática de Cuidados Paliativos.

Em 2011, a medicina paliativa foi reconhecida como área de atuação médica pela Associação Médica Brasileira e pelo Conselho Federal de Medicina, fato que não exclui os cuidados paliativos do âmbito de estudo e prática de outros profissionais da saúde como psicólogos, enfermeiros, nutricionistas, fisioterapeutas, entre outros envolvidos neste tipo de assistência ao paciente.

Cuidados Paliativos $^{3}$ é uma forma de assistência prestada por equipe multiprofissional que visa à melhoria da qualidade de vida de pacientes e familiares que enfrentam doenças ameaçadoras à vida, com o controle da dor e do sofrimento físico, psicológico e espiritual e a individualização dos cuidados a partir da necessidade e dos desejos dos pacientes e de seus familiares.

O Código de Ética Médica de 2009 erige à condição de princípio fundamental os cuidados paliativos em seu inciso XXII: "Nas situações clínicas irreversíveis e terminais, o médico evitará a realização de procedimentos diagnósticos e terapêuticos desnecessários e propiciará aos pacientes sob sua atenção todos os cuidados paliativos apropriados” (CFM, 2009).

3 Segundo a definição da Organização Mundial de Saúde - OMS, revista em 2002, "Cuidado Paliativo é uma abordagem que promove a qualidade de vida de pacientes e seus familiares, que enfrentam doenças que ameacem a continuidade da vida, através da prevenção e alívio do sofrimento. Requer a identificação precoce, avaliação e tratamento da dor e outros problemas de natureza física, psicossocial e espiritual”. (OMS, 2002) 
Mas quais seriam os procedimentos considerados desnecessários, extraordinários ou fúteis? Como decidir se determinado procedimento salva uma vida ou apenas prolonga a dor e o sofrimento? Que significa a condição de paciente terminal?

A elaboração de uma definição de paciente terminal é complexa, mas parece haver um consenso de que, embora de difícil conceituação, é fácil observá-la na prática. "A terminalidade parece ser o eixo central do conceito em torno da qual se situam as consequências. É quando se esgotam as possibilidades de resgate das condições de saúde do paciente e a possibilidade de morte próxima parece inevitável e previsível”, segundo (GUTIERREZ, 2001). O paciente terminal, portanto, depara o dilema da anunciação da morte próxima sem que a ciência possa reverter este futuro.

Nessa fase terminal, o cuidar da pessoa doente deve prevalecer sobre o tratamento da doença. Os cuidados paliativos, com o controle da dor e do sofrimento físico e emocional, devem se sobrepor ao tratamento curativo, possibilitando ao enfermo o máximo de conforto e dignidade possíveis em seus momentos finais. Tratamentos destinados a pacientes agudamente enfermos em Unidades de Terapia Intensiva (UTI's), como, por exemplo, paciente após infarto do miocárdio ou após sofrer um trauma em acidente automobilístico não devem ser os mesmos destinados a paciente portadores de doenças crônico degenerativas em estado de terminalidade.

De acordo com Girond (2006) “a reanimação cardíaca, a respiração artificial, infusões intravenosas, antibioticoterapia e outros procedimentos invasivos são todas medidas de suporte primárias, para auxiliar o paciente no período inicial de recuperação da saúde". Tais procedimentos são considerados invasivos ou desproporcionais quando oferecidos a paciente cuja reversibilidade da doença não é possível.

Conquanto dramática seja a escolha do melhor tratamento médico ao paciente, necessária a tomada de decisão compartilhada. Nesse momento, o profissional da saúde, detentor do conhecimento específico, estabelece um diálogo esclarecedor com o enfermo, mitigando as dúvidas e oferecendo possibilidades de tratamento. A comunicação é parte do cuidado de saúde e pode resultar em diferenças quanto ao tratamento escolhido pelo paciente ou por seus familiares ou quanto ao luto vivido por estes (AZOULAY, et al, 2005) (LAUTRETTE, et al, 2007) $)^{4}$.

$4 \mathrm{O}$ estudo realizado pelo grupo de Azoulay, em 22 UTI's da França, tinha como objetivo avaliar o luto dos familiares após 90 dias do óbito do paciente internado. No estudo, o paciente elegível era randomizado para um 
Surge um impasse, contudo, quando o paciente não pode manifestar sua vontade. As diretivas antecipadas da vontade apresentam-se como uma resposta possível e, mais que isso, necessária.

O instituto foi introduzido e é regulamentado no Brasil pela Resolução no 1995 do CFM. Ante a ausência de legislação específica sobre a matéria, a entidade médica pretendeu regulamentar a atuação médica, protegendo a classe de eventuais responsabilidades cível e penal e, também, ampliando a autonomia do paciente em seu decidir de acordo com a alteração na relação médico-paciente experimentada ao longo dos séculos.

$\mathrm{O}$ artigo $1^{\circ}$ define as diretivas como o "conjunto de desejos, prévia e expressamente manifestados pelo paciente, sobre cuidados e tratamentos que quer, ou não, receber no momento em que estiver incapacitado de expressar, livre e autonomamente, sua vontade" (CFM, 2009).

Essa é a forma de diretiva chamada testamento vital, denominação que decorre da tradução da expressão norte-americana living will. No entanto, é bastante criticada pela confusão terminológica a que conduz, pois testamento refere-se a uma manifestação prévia da vontade, mas que tem sua eficácia somente após a morte do testador. Já nas diretivas, a vontade do paciente deve ser cumprida em vida (ALVES, FERNANDES, GONDIM, 2012). As diretivas também permitem ao paciente a escolha de um representante, instituindo um mandato duradouro para que alguém lhe substitua a vontade sobre os cuidados médicos aos quais será submetido.

$\mathrm{Na}$ ausência de uma diretiva antecipada em que o paciente manifeste seus desejos sobre os cuidados no fim da vida e impossibilitado de fazê-lo pela falta de discernimento, cabe à família decidir sobre como se dará a sua morte. Entretanto, nem sempre a decisão ocorre de forma uníssona, alcançando um consenso entre os diversos familiares.

Pelo contrário, comumente composta por mais de um indivíduo com diferentes perspectivas sobre a vida, seus limites e sobre o processo de morrer, a família, em seu decidir, enfrenta um dilema em busca da escolha correta e, por vezes, acaba por contrariar a vontade do paciente expressa em uma conversa informal, mas não em um documento.

grupo de controle, onde a equipe médica conversava com o paciente de forma habitual. No grupo de intervenção, eram realizadas conferências com a família do paciente e com os profissionais que o assistiam que foram orientados a utilizar a regra mnemônica chamada em inglês de VALUE. Os resultados mostraram que no grupo de intervenção, o suporte artificial de vida com drogas vasoativas e ventilação mecânica foram mais frequentemente retirados. Também se observou que os familiares deste grupo apresentaram menor índice de síndrome de estresse pós-trauma, menos sintomas de ansiedade e depressão e menor uso de medicações psiquiátricas 90 dias após o óbito. 
A angústia de enfrentar a morte de um familiar e o medo do sentimento de culpa por não ter feito "tudo o que podia" pode levar à obstinação terapêutica, em que o paciente é mantido vivo no sentido biológico, mas em constante sofrimento pelo prolongamento da vida sem um mínimo de conforto. Assim, aliar ambas as espécies de diretivas - o testamento vital e o mandato duradouro - em um único documento pode ser um meio eficaz de ver cumprida a vontade do paciente na sua autonomia para morrer (PENALVA, 2010).

As diretivas foram objeto de discussão jurídica. O Ministério Público Federal de Goiás provocou o poder judiciário local, por meio de Ação Civil Pública (GOIÁS, 2013), para que se manifestasse sobre a legalidade e constitucionalidade da Resolução no 1995/12, do CFM. A decisão do magistrado de $1^{\circ}$ grau foi pela improcedência do pedido, concluindo pela compatibilidade das diretivas antecipadas da vontade com o ordenamento jurídico brasileiro.

Para fundamentar sua decisão, o magistrado recorreu aos princípios constitucionais da dignidade da pessoa humana $\left(\mathrm{CF}\right.$, art. $\left.1^{\circ}, \mathrm{III}\right)$, da autonomia da vontade $\left(\mathrm{CF}\right.$, art. $5^{\circ}$, caput e II) e da vedação à tortura ou a tratamento desumano ou degradante $\left(\mathrm{CF}\right.$, art. $\left.5^{\circ}, \mathrm{III}\right) . \mathrm{Na}$ petição autoral, o MPF recorreu ao princípio da inviolabilidade da vida $\left(\mathrm{CF}\right.$, art. $5^{\circ}$, caput) para fundamentar o seu pedido. Assim, uma análise da constitucionalidade das diretivas perpassa pelos supracitados princípios.

O direito à vida é defendido por alguns como o direito mais fundamental de todos, pois essencial para o gozo dos demais, sendo um pressuposto à existência humana (MORAES, 2000, p. 61).

O direito à autonomia, uma dentre as várias manifestações do direito à liberdade, permite ao indivíduo a capacidade de autogoverno, para que possa decidir, de acordo com seus valores, objetivos, sentimentos e suas crenças sobre seu modo de viver (SARMENTO, 2003).

O princípio da dignidade da pessoa humana é um metaprincípio que norteia a interpretação e aplicação de toda a Constituição Federal. Erigido a um dos fundamentos da República Brasileira, trata-se não apenas de um princípio jurídico, "mas o é também da ordem política, econômica e social” (DA SILVA, 1998, p. 92). No entanto, o princípio é polissêmico, de difícil conceituação e alto grau de abstração (MALUSCHKE, 2007), pelo que pode conduzir a diferentes interpretações e, portanto, decisões jurídicas.

Ao se falar das diretivas, o princípio poderia, de um lado, fundamentar o direito inviolável à vida e a consequente ilegalidade das diretas ao considerá-las uma afronta à vida 
humana. De outro lado, o metaprincípio poderia fundamentar a constitucionalidade das diretivas e o direito à autonomia do paciente para determinar-se de acordo com seus valores sobre as decisões no fim da vida.

No ordenamento jurídico brasileiro não há valores absolutos que possuam prioridade absoluta. Todos os direitos e valores devem ser respeitados na maior medida possível. Em um caso como este da Ação Civil Pública, deve o intérprete ponderar os princípios para alcançar uma decisão justa e de acordo com a Constituição e com a doutrina constitucional.

$\mathrm{Na}$ referida decisão, o magistrado entendeu que a autonomia do paciente para manifestar previamente sua vontade sobre os cuidados e tratamentos que deseja ou não receber não ferem a inviolabilidade da vida e, assim, recebem guarida constitucional.

\section{A MORTE DE IVAN ILITCH}

Literatura e Direito, ciência e arte, estão em conexão e em constante troca mútua, uma repercutindo na outra. A literatura pode auxiliar no processo de compreensão e interpretação do Direito. A ficção revela o que a sociedade de determinados lugar e tempo pensa sobre o Direito e a administração da Justiça. (DWORKIN, 2000, p. 217 e ss).

Em A morte Ivan Ilicth, o autor guia o leitor a uma reflexão sobre a morte, a transitoriedade da vida e a dificuldade de aceitá-la. O protagonista, que sempre viveu comme il faut ${ }^{5}$, ao fazer a mudança para sua nova casa sofre uma queda, que de imediato não lhe preocupa, aparentando-lhe um simples machucado. Entretanto, passado algum tempo, sente um gosto amargo na boca e um incômodo no lado esquerdo do estômago, sensações que lhe trazem mau humor ininterrupto e prejudicam a convivência "alegre e decente" com a família. Preocupado, o juiz procura um médico.

Tudo se passou como esperava, isto é, como sempre acontece nessas ocasiões: a espera, um ar importante e artificial, doutoral, que já conhecia, aquele mesmo que ele sabia que tinha no tribunal, as batidas no paciente, a auscultação, as perguntas que exigiam respostas formuladas de antemão e, ao que parece, desnecessárias, a expressão significativa, que sugeria o seguinte: basta que você se submeta a nós, e havemos de arranjar tudo, sabemos sem nenhuma dúvida como arranjá-lo, temos um padrão único para todas as pessoas. (TOLSTÓI, 2009, p. 37)

5 Em francês: como é preciso. (Notas do Tradutor - Tradução de Boris Schnaiderman). Tolstói utiliza várias expressões em língua francesa em sua obra, prática comum à aristocracia russa da segunda metade do século XIX. 
Todavia, a consulta médica não lhe solveu a dúvida mais importante: "a sua condição apresentava perigo? O doutor não conferia importância a essa questão inconveniente" (TOLSTÓI, 2009, p. 37). Nesse trecho, o autor faz uma crítica tanto ao médico em sua relação com o paciente quanto ao juiz no tribunal, demonstrando relações exclusivamente funcionais, marcadas pelo distanciamento do outro, pelo procedimentalismo e pela negligência na dimensão humana.

O primeiro médico consultado importou-se com a doença e em encontrar o diagnóstico, mas se esqueceu da comunicação com o paciente, de tratar o doente. Ao longo da narrativa, Ivan Ilitch procura outros médicos famosos a fim de encontrar um diagnóstico e uma cura para sua dor. Entretanto, cada médico fazia novas perguntas, novos exames e novos diagnósticos, deixando-o confuso, mas nenhum falava sobre a gravidade da doença que o acometia.

No período em que foi escrita esta novela, predominava na medicina o modelo paternalista na relação médico-paciente, em que o médico - profissional detentor do conhecimento científico - decidia pelo paciente, assumindo este um papel passivo e “dependente do julgamento e das ideias do médico" (CAPRARA, et al, 1999). Neste modelo, opta-se por ocultar do paciente a gravidade de sua doença, no intuito de preservá-lo do sofrimento do prognóstico.

Mas Ivan Ilitch sabia. "Não podia mentir a si mesmo: acontecia nele algo terrível, novo e muito significativo, o mais significativo que lhe acontecera na vida. E era o único a sabê-lo, todos os que o cercavam não compreendiam ou não queriam compreender isto". (TOLSTÓI, 2009, p. 41).

A certeza de que a morte se aproximava o acompanhava em todas as suas atividades diárias. Já não conseguia concentrar-se nos casos jurídicos que lhe apareciam; conduzir as audiências no tribunal tornara-se embaraçoso, pois vivia imerso na resolução de seu próprio caso, de sua doença. Em casa, vivia mal humorado e qualquer pequeno inconveniente era motivo para discussões com a esposa ou os filhos. Ilitch sentia-se sozinho, sem ninguém que o compreendesse.

Além dessa mentira [a dificuldade dos familiares e amigos de aceitarem a morte], ou em consequência dela, o que mais atormentava Ivan Ilitch era o fato de que ninguém se compadecesse dele da maneira como ele queria: havia instantes, depois de prolongados sofrimentos, em que Ivan Ilitch queria mais que tudo, por mais que se envergonhasse de confessá-lo, que alguém se apiedasse dele como de uma criança 
doente. Queria ser acarinhado, beijado, que chorassem sobre ele, como se costuma acarinhar e consolar crianças. Ele sabia que era um juiz importante, que em parte já tinha uma barba grisalha, e que por isto seria impossível; mas, assim mesmo, queria. (TOLSTÓI, 2009, p. 57).

O único que parecia compreendê-lo era Guerássim, um ajudante de copeiro, mujique, jovem e forte. Certa vez, auxiliando o patrão enfermo, em uma de suas atividades diárias, o jovem elevou os pés de Ilitch, o que provocou uma imediata sensação de alívio. A partir de então, ambos desenvolveram uma relação de amizade e compreensão, e, por vezes, o ajudante de copeiro passava a noite com os pés de Ilitch erguido em seus ombros, produzindo uma espécie de conforto e cuidado.

Ainda, Guerássim não mentia nem ocultava a verdade da proximidade da morte de Ilitch. Ao contrário, encarava-a com franqueza e naturalidade, aceitando o destino final comum a todos e compadecendo-se do moribundo. "De uma feita, até disse francamente, quando Ivan Ilitch o mandava embora: - Todos nós vamos morrer. Por que então não me esforçar um pouco?” (TOLSTÓI, 2009, p. 56).

Em outra consulta médica, sua esposa reclamara que Ilitch sempre deixava de fazer algo necessário, de seguir alguma prescrição para os seus cuidados - esta era a relação de Prascróvia com a doença: sempre reclamava de algum comportamento indevido do marido no cumprimento das recomendações médicas e o repreendia amorosamente, ignorando a gravidade da situação.

Em seguida, a esposa comentou com o médico sobre a posição de que Ilitch gostava de se deitar, com as pernas pra cima. "Ela contou como ele obrigava Guerássim a segurar-lhe os pés. O doutor sorriu com desdém e carinho, o que significava: 'Ora, que remédio? Esses doentes inventam às vezes cada bobagem; mas pode-se desculpar"”. (TOLSTÓI, 2009, p. 61)

Ilitch não recebeu a assistência profissional adequada. A preocupação com o conforto físico e emocional - pontos cruciais dos cuidados paliativos - não lhe foi ofertada pelos médicos famosos a quem recorreu. Os seus amigos, colegas de profissão, tampouco seus familiares mais próximos pareciam compreender a sua dor, sua necessidade de conversar sobre a morte ou seu desejo de cuidado como se cuida de uma criança.

Em outra cena, Tolstói relata um pensamento de Ilitch comum a todos os homens: a certeza da mortalidade, mas a dificuldade de encarar e aceitar a sua própria morte. 
O exemplo do silogismo que ele aprendera na Lógica de Keisewetter: Caio é um homem, os homens são mortais, logo Caio é mortal, parecera-lhe durante toda a sua vida, correto somente em relação a Caio, mas de modo algum em relação a ele. Tratava-se de Caio-homem, um homem em geral, e neste caso era absolutamente justo; mas ele não era Caio, não era um homem em geral, sempre fora um ser completa e absolutamente distinto dos demais; ele era Vânia ${ }^{6}$, com mamãe, com papai, com Mítia e Volódia ${ }^{7}$, com os brinquedos, o cocheiro, a babá, depois com Kátienka ${ }^{8}$, com todas as alegrias, tristezas e entusiasmos da infância, da juventude, da mocidade. Existiu porventura para Caio aquele cheiro da pequena bola de couro listrada, de que Vânia gostava tanto?! Poventura Caio beijava daquela maneira a mão da mãe, acaso farfalhou para ele, daquela maneira, a seda das dobras do vestido da mãe? Fizera um dia tanto estardalhaço na Faculdade de Direito por causa de um pirojki? ? Estivera Caio assim apaixonado? E era capaz de conduzir assim uma sessão de tribunal?

E Caio é realmente mortal, e está certo que ele morra, mas quanto a mim, Vânia, Ivan Ilitch, com todos os meus sentimentos e ideias, aí o caso é bem outro. E não pode ser que eu tenha de morrer. Seria demasiadamente terrível. (TOLSTÓI, 2009, p. 49).

Ivan Ilitch não teve uma morte com dignidade. Seus gritos "duraram três dias a fio, e eram tão terríveis a ponto de não se poder ouvi-los sem um sentimento de horror, mesmo atrás de duas portas" (TOLSTÓI, 2009, p. 74). A dor física e o assombro de seu fim atormentaramno e ele não parava de se questionar como aquilo pudera lhe acontecer, logo com ele que sempre vivera bem, vivera de acordo como se deveria - comme il faut.

Foi ao fim de sua jornada que o protagonista compreendeu como fora a sua existência e resignou-se. A vida que levara em busca da aprovação da sociedade o distanciara cada vez mais da inocência e honestidade que lhe eram tão claras nas memórias de sua infância feliz.

O casamento e as amizades por conveniência - no início da narrativa vê-se a preocupação da esposa quanto a como se obter o máximo de dinheiro do tesouro com a morte de Ilitch; quantos aos colegas do universo judiciário, a preocupação é com quem assumirá o posto do falecido - não mais lhe eram suficientes. "Via neles a si mesmo, tudo aquilo que vivera, e via claramente que tudo aquilo era não o que devia ser, mas um embuste horrível, descomunal, que ocultava tanto a vida como a morte". (TOLSTÓI, 2009, p. 72)

Após três dias de dor e sofrimento, uma hora antes de sua morte:

Ilitch caiu no fundo, viu a luz e percebeu que a sua vida não fora o que devia ser, mas que ainda era possível corrigi-lo. Perguntou a si mesmo: 'mas o que é aquilo?' -

6 Diminutivo de Ivan. (Notas do Tradutor)

7 Diminutivos de Dmitrí e Vladímir, respectivamente. (N. do T.)

8 Diminutivo de Iecatierina (Catarina). (N. do T.)

9 Espécie de bolinhos recheados. (N. do T.) 
e silenciou, o ouvido atento. Sentiu então que alguém lhe beijava a mão. Abriu os olhos e dirigiu-os para o filho. Teve pena dele. A mulher aproximou-se. Olhou-a. Ela também o olhava, a boca aberta, uma expressão de desespero e tendo lágrimas não enxugadas sobre o nariz e a face. Teve pena dela. (TOLSTÓI, 2009, p. 75)

Com pena do filho, pediu para a mulher retirá-lo dali. E pediu para que ela se retirasse também. "Quis dizer 'perdoa-me, mas disse 'deixe-me passar'"10 e não tendo mais força para corrigir o lapso, esboçou um gesto de renúncia, sabendo que seria compreendido por quem importava". (TOLSTÓI, 2009, p. 75)

Esse clássico da literatura ao ter como ponto central a morte, aponta como é necessário refletir sobre ela para que se possibilite uma morte com dignidade, mas mais que isso, o poeta russo demonstra que uma reflexão sobre a morte, é, também, sobre a vida; sobre como se quer ou como se deveria viver.

\section{DESAFIOS ATUAIS}

Estamos vivendo um período de anormalidade. A Organização Mundial da Saúde declarou o estado de pandemia provocada pela disseminação de uma nova espécie do vírus corona: o covid-19. O vírus é capaz de infectar novas pessoas com facilidade e a transmissão da doença pode se dar de forma contínua e eficiente.

A principal medida de combate ao vírus é o isolamento social; o que foi decretado por diversos países ao redor do globo, incluindo o Brasil. A medida afeta drasticamente a economia, sendo previsto um período de recessão mundial, mas se mostra essencial para diminuir a disseminação do vírus e, assim, salvar vidas.

Embora haja um grupo de risco específico para a doença: pessoas com maior de 60 anos e pessoas com alguma comorbidade pré-existente como diabetes, doença cardiovascular, doença respiratória crônica, entre outras; a doença também mata pessoas jovens e saudáveis. Além disso, há pessoas assintomáticas que causam preocupação na disseminação do vírus, pois, apesar de não apresentarem qualquer sintoma da doença, podem espalhar para outros.

A doença, nos casos graves, provoca a pneumonia como uma patologia relacionada e causa uma síndrome respiratória aguda, o que pode ser mortal. (XU, et al, 2020) Por conseguinte, aumentou a busca por respiradores de ventilação mecânica para o tratamento dos paciente bem como por equipamentos de proteção individual para evitar a contaminação dos

10 Em russo: "prosti” e "propust”, respectivamente. (Notas do Tradutor - Tradução de Boris Schnaiderman) 
profissionais de saúde que lidam diretamente no combate ao vírus e a construção de leitos de UTI para o recebimento e tratamento dos infectados.

$\mathrm{Na}$ Itália, onde o número total de mortos da doença do covid-19 ultrapassou a faixa dos dezoito mil, relatos de médicos alertavam para o pesadelo que os pacientes viviam, ao morrerem sozinhos, isolados em um leito de UTI, sem poderem se despedir de seus familiares. Um grupo de militantes do partido democrático de Milão, então, deu início a uma campanha para que os pacientes pudessem se despedir de seus familiares em seus momentos finais. A iniciativa foi chamada "o direito de dizer adeus" e distribuiu tablet's nos Hospitais para que os pacientes pudessem, uma última vez, cumprimentar seus entes queridos. (BBC, 2020)

$\mathrm{Na}$ Espanha, o exponencial no número de mortos levou a uma crise funerária e uma pista de patinação de gelo foi utilizada para conservar os corpos dos mortos (ESTADO DE MINAS, 2020). No Estado de Nova York, epicentro da pandemia nos EUA, um vídeo divulgado pela rede britânica $\mathrm{BBC}$ mostra um enterro em massa das vítimas em valas comuns (JORNAL DE BRASÍLIA, 2020). Imagens de corpos sendo carregados por retroescavadeiras também chocam a população. No Equador, o colapso do sistema funerário levou a situações extremas de mortos permanecerem até três dias em casa, esperando pelos serviços funerários. $\mathrm{O}$ risco de proliferação fez com que os velórios fossem suspensos no Brasil (AGENCIA BRASIL, 2020).

As cenas relatadas dizem respeito a uma situação de anormalidade, mas revelam a necessidade de se pensar o direito à morte com dignidade. Discutir a mortalidade, ainda mais em um período de crise de saúde global, não é tarefa fácil.

A literatura (GAWANDE, 2015), o cinema (DANTAS, MARTINS, MILITÃO, 2011) e as artes em geral auxiliam no enfrentamento de tema tão delicado, mas a ciência deve, também, imiscuir-se no debate. A medicina com a evolução dos Cuidados Paliativos e o Direito com as Diretivas Antecipadas da Vontade interconectam-se na função de garantir dignidade no morrer.

Foi com o avanço tecnológico na Medicina e o aumento de aparelhos de suporte vital que as discussões sobre os limites terapêuticos iniciaram. Procedimentos como a nutrição e hidratação artificiais (NHA), a utilização de respiradores artificiais e infusões intravenosas podem prolongar a vida biológica, mas a custo do conforto e da qualidade de vida de um paciente moribundo, cuja cura não existe e a morte não pode ser evitada. 
Se na época de Ivan Ilitch e de, Tolstói, seu criador, a morte dava-se em casa, junto aos familiares que acompanhavam de perto a finitude do moribundo e vivenciavam a morte e o luto de perto; atualmente, a maior parte da população termina seus dias em Unidades de Terapia Intensiva, conectada a aparelhos de suporte vital, isolada e distante do contato com seus familiares e amigos, devido à rígida e necessária rotina nas UTI's. (NUNES, MELO, 2011)

As diretivas antecipadas da vontade mostram-se como uma opção ao enfermo de evitar a obstinação terapêutica ou futilidade médica com o uso de medidas desproporcionais que prolongam o sofrimento e a dor. O paciente ao dispor previamente seu desejo sobre os cuidados médicos de fim da vida tem sua autonomia ampliada e pode também, por outro lado, decidir-se pelo máximo de esforço terapêutico a ser realizado para garantia de sua vida (PESSINI, DE BARCHIFONTAINE, 1997).

As diretivas não impõem um modelo a ser observado pelo paciente, mas, ao contrário, asseguram sua autonomia para decidir livremente como será o fim de sua biografia. E, assim, pode o indivíduo manifestar-se de acordo com seus princípios, crenças e valores.

Além disso, o instituto jurídico pode ser o diferencial no processo de luto dos familiares. Sem um documento no qual conste as vontades do paciente, a família é chamada a decidir, substituindo-lhe a vontade. Contudo, a responsabilidade de decidir sobre a vida e a morte de um familiar pode se tornar um encargo que dificulta a despedida e aumenta o medo.

O estudo Support (Study to understand prognosis and preferences for outcomes and risk of treatment) tinha como objetivo caracterizar a experiência de morrer na perspectiva dos tomadores de decisão substitutos, geralmente familiares. O método utilizado foi a avaliação de prontuários médicos com para a escolha de pacientes gravemente enfermos ou com idade superior a 80 anos que faleceram e para quem foi necessário um tomador de decisão substituto. O método também inclui uma entrevista com estes. (LYNN, 1997)

Segundo esse estudo, 55\% dos pacientes avaliados estiveram conscientes nos três dias antecedentes à morte; $40 \%$ sofreram dores insuportáveis; $80 \%$, fadiga extrema e 63\%, extrema dificuldade para tolerar o sofrimento físico e emocional. Entre as conclusões, está, também, a de que a maioria dos pacientes idosos e gravemente enfermos morreu em Hospitais de Cuidados Intensivos e de que, apesar de os membros da família acreditarem que os pacientes preferiam conforto, os tratamentos de manutenção da vida eram frequentemente utilizados (DE SIQUEIRA, 2011). 
Um ponto a ser esclarecido é que as diretivas não permitem a prática da eutanásia. Eutanásia, deriva do grego euthanasía - eu, que significa bem, e thanasia, que significa morte, ou seja, a palavra designa uma morte boa, tranquila. (MARTIN, 1998, p. 82) ao distinguir as diferentes práticas médicas relacionadas ao fim da vida, conceitua eutanásia como "atos médicos que, motivados por compaixão, provocam precoce e diretamente a morte a fim de eliminar a dor".

A prática seria, assim, uma forma de abreviar a vida com a intenção de acabar com o sofrimento do paciente. O ordenamento jurídico brasileiro condena a $\operatorname{conduta}^{11}$ e a criminaliza, sendo julgada pelos tribunais pátrios como um homicídio privilegiado "ou seja, cometido por motivo de relevante valor moral, quer dizer, cometido em decorrência de interesse particular e, por isso, é causa de atenuação da pena inicialmente prevista para o crime" (DODGE, 2009).

O Código de Ética Médica também proíbe a conduta em seu artigo 41: “é vedado ao médico abreviar a vida do paciente, ainda que a pedido deste ou de seu representante legal" (CFM, 2009, p. 39). A norma, logo após, no parágrafo único, do referido artigo, esclarece que oferecer cuidados paliativos não se confunde com a prática da eutanásia. A vontade do paciente expressamente manifesta deve ser respeitada ou, na sua impossibilidade a de seu representante, e evitar procedimentos fúteis ou desproporcionais não significa abreviar a vida, mas aceitar o seu curso natural.

\section{CONSIDERAÇÕES FINAIS}

O silogismo de Caio a que Ivan Ilitch se refere é comum a todos. Uma característica universal a humanidade é a mortalidade e, ainda que não se saiba como, onde, quando ou de quê se vai morrer, sabe-se da inevitabilidade da morte. Mesmo aceitando-a como parte integrante da existência humana, como algo natural, nunca será fácil o morrer, despedir-se de tudo e de todos sem saber como será o depois. (HORTA, 2009).

Além disso, do sofrimento emocional e espiritual, a morte geralmente vem acompanhada de dor. A debilidade do corpo humano doente e enfraquecido provoca

11 Art. 121. Matar alguém:

$\S 1^{\circ}$ Se o agente comete o crime impelido por motivo de relevante valor social ou moral, ou sob o domínio de violenta emoção, logo em seguida a injusta provocação da vítima, o juiz pode reduzir a pena de um sexto a um terço. Código Penal. 
sofrimento físico ao moribundo e os cuidados paliativos são uma maneira de tratar a dor para que o paciente possa experimentar a morte com dignidade, viver este momento final e despedir-se de sua família e amigos e, mesmo, de sua vida.

As diretivas são mais um meio pensado para auxiliar as pessoas no processo de morrer. $\mathrm{O}$ paciente é o titular do direito à vida e também do direito à autonomia, cabe a ele autodeterminar-se e decidir como se dará a sua morte; "a pessoa em princípio é mais qualificada para avaliar e decidir o rumo de sua vida" (SCHRAMM, 2011).

Tolstói, com sua obra literária, mostra a necessidade do homem de falar sobre a morte, de expressar seus medos e sua agonia, e de sentir-se acolhido e amparado pelos seus pares. Ao contrário do senso comum, falar sobre a morte não é um agouro. Discutir os cuidados médicos com os pacientes moribundos não traduz uma idolatria à morte, mas um respeito a esse momento, entendendo sua significância na existência humana.

\section{REFERÊNCIAS}

A Campanha na Itália para que pacientes terminais com coronavírus possam dizer adeus a familiares. BBC-BRASIL, 23 de março de 2020. Disponível em <https://www.bbc.com/portuguese/internacional-52005958>. Acesso em 10 de abril de 2020.

ALVES, Cristiane Avancini; FERNANDES, Marcia Santana; GOLDIM, José Roberto. Diretivas antecipadas de vontade: um novo desafio para a relação médico-paciente. Clinical \& Biomedical Research, v. 32, n. 3, 2012.

AZOULAY, Elie et al. Risk of post-traumatic stress symptoms in family members of intensive care unit patients. American journal of respiratory and critical care medicine, $v$. 171, n. 9, p. 987-994, 2005.

BRASIL. Constituição (1988). Constituição da República Federativa do Brasil. Brasília: Senado Federal - Secretaria Especial de Editoração e Publicações, 2013.

CAPRARA, Andrea et al. A relação paciente-médico: para uma humanização da prática médica. Cadernos de Saúde Pública, v. 15, n. 3, p. 647-654, 1999.

CAZARRÉ, Marieta. Sistema funerário do Equador entra em colapso por mortes pela covid19. Agência Brasil, Montevidéu, 02 de abril de 2020. Disponível em $<$ https://agenciabrasil.ebc.com.br/saude/noticia/2020-04/sistema-funerario-do-equador-entraem-colapso-por-mortes-pela-covid-19>. Acesso em 10 de abril de 2020.

CECILIO, Luiz Carlos de Oliveira. A morte de Ivan Ilitch, de Leon Tolstói: elementos para se pensar as múltiplas dimensões da gestão do cuidado. Interface-Comunicação, Saúde, Educação, v. 13, p. 545-555, 2009.

CONSElHO FEDERAL DE MEDICINA. Código de Ética Médica de 2009. 
CONSELHO FEDERAL DE MEDICINA. Resolução $\mathbf{n}^{\mathbf{0}} \mathbf{1 . 9 9 5}$, de 09 de agosto de 2012. Dispõe sobre as diretivas antecipadas de vontade dos pacientes.

DANTAS, Anielle Avelina; MARTINS, Carlos Henrique; MILITÃO, Maria Socorro Ramos. O cinema como instrumento cidático para a abordagem de problemas bioéticos: uma reflexão sobre a eutanásia. Revista Brasileira de Educação Médica, v. 35, n. 1, p. 69-76, 2011.

DA SILVA, José Afonso. A dignidade da pessoa humana como valor supremo da democracia. Revista de direito administrativo, v.212, p. 89-94, 1998.

DE SIQUEIRA, José Eduardo. Definindo e aceitando a terminalidade da vida. Conflitos bioéticos do viver e do morrer. Brasília, Brasil: Câmara Técnica sobre Terminalidade do Conselho Federal de Medicina, p. 15-24, 2011.

DODGE, Raquel E. Ferreira. Eutanásia-aspectos jurídicos. Revista Bioética, v. 7, n. 1, p. 1320, 2009.

DWORKIN, Ronald. Uma questão de princípio. São Paulo: Martins Fontes, 2000.

GALVÃO, Paulo. Coronavírus: pista de patinação no gelo é usada para conservar cadáveres na Espanha. Estado de Minas - Internacional, 24 de março de 2020. Disponível em <https://www.em.com.br/app/noticia/internacional/2020/03/24/interna_internacional,1131916 /coronavirus-pista-de-patinacao-e-usada-para-conservar-cadaveres.shtml >. Acesso em 10 de abril de 2020.

GAWANDE, Atul. Mortais: nós, a medicina e o que realmente importa no final. Objetiva, 2015 .

GIROND, Juliana Balbinot Reis; WATERKEMPER, Roberta. Sedação, eutanásia e o processo de morrer do paciente com câncer em cuidados paliativos: compreendendo conceitos e inter-relações. Cogitare Enfermagem, v. 11, n. 3, p. 258-263, 2006.

GOIÁS. Justiça Federal. Ação Civil Pública n. ${ }^{\circ}$ 1039-86.2013.4.01.3500/Classe:7100. Requerente: Ministério Público Federal. Requerido: Conselho Federal de Medicina. Juiz: Eduardo Pereira da Silva. Goiânia, jan. 2013.

GUTIERREZ, Pilar L.. O que é o paciente terminal?. Rev. Assoc. Med. Bras., São Paulo , v. 47, n. 2, p. 92, junho de 2001.

HORTA, Márcio Palis. Eutanásia-Problemas éticos da morte e do morrer. Revista bioética, v. 7, n. 1, 2009.

KÜBLER-ROSS, Elisabeth. Sobre a morte e o morrer: O que os doentes terminais têm para ensinar a médicos, enfermeiras, relogiosos e aos seus próprios parentes. WWF Martins Fontes, 2017.

LAUTRETTE, Alexandre et al. A communication strategy and brochure for relatives of patients dying in the ICU. New England Journal of Medicine, v. 356, n. 5, p. 469-478, 2007.

LYNN, Joanne et al. Perceptions by family members of the dying experience of older and seriously ill patients. Annals of internal medicine, v. 126, n. 2, p. 97-106, 1997. 
MALUSCHKE, Günther. A dignidade humana como princípio ético-jurídico. Nomos: Revista do Curso de Mestrado em Direito da UFC, Fortaleza, v. 27, p. 95-117, jul./dez.2007.

MARTIN, Leonard M. Eutanásia e distanásia. Iniciação à Bioética. Brasília: Conselho Federal de Medicina, p. 171-192, 1998.

MORAES, Alexandre de. Direito Constitucional. $8^{a}$ ed. São Paulo. Editora Atlas S.A. 2000.

NUNES, Rui; MELO, Helena Pereira de. Testamento Vital. Lisboa, Portugal. Faculdade de Direito Universidade Nova Lisboa. Brasil, Almedina, 2011. Pág. 52

ORGANIZAÇÃO MUNDIAL DA SAÚDE (OMS). Envelhecimento Ativo: Um Quadro de Políticas. Genebra: OMS. 2002.

PENALVA, Luciana Dadalto. Declaração prévia de vontade do paciente terminal. Revista Bioética, v. 17, n. 3, 2010.

PESSINI, Leocir; DE BARCHIFONTAINE, Christian de Paul. Problemas atuais de bioética. Edições Loyola, 1997.

POSNER, Richard. Law \& Literature. Cambridge/London: Harvard University Press, 2009.

SARMENTO, Daniel. Os princípios constitucionais da liberdade e da autonomia privada. Dos princípios constitucionais: considerações em torno das normas principiológicas da Constituição Org. George Salomão Leite. São Paulo: Malheiros, 2003.

SCHRAMM, Fermin R., and Fermin Roland Schramm. "? Por qué la definición de muerte no sirve para legitimar moralmente la eutanásia y el suicidio asistido?." (2001). Perspectivas Bioéticas, v. 6, p. 43-54, 2011.

TOLSTOI, Lev. A morte de Ivan Ilitch. Tradução: Boris Schnaiderman. Editora 34, 2009.

TRINDADE, André Karam; ROSENFIELD, Luis. Réquiem para Ivan Ilitch: o problema da interpretação do direito na literatura de Tolstói. Revista da Faculdade de Direito UFPR, v. 60, n. 2, p. 157-176, 2015.

VIDEO: Nova York começa a cavar fossas comuns para vítimas de vírus. Jornal de Brasília, Brasília, 10 de abril de 2020. Disponível em https://jornaldebrasilia.com.br/mundo/nova-yorkcomeca-a-cavar-fossas-comuns-para-vitimas-de-virus/. Acesso em 11 de abril de 2020.

XU, Zhe et al. Achados patológicos do COVID-19 associados à síndrome do desconforto respiratório agudo. The Lancet medicine respiratória , v. 8, n. 4, p. 420-422, 2020. 